\title{
A Case of Idiopathic Progressive Middle Cerebral Arteriopathy in A Child with a Lenticulostriate Stroke and the Cerebral Perfusion Improvement after Edas Surgery
}

\author{
Pereira CCS ${ }^{1 *}$, Gabriel Scarabôtolo Gattás ${ }^{2}$, Douglas Mendes Nunes ${ }^{2}$, Rafael Fernandes nunes ${ }^{3}$, Daniela Barbieri \\ Bariani $^{4}$ and Americo Rubens Leite ${ }^{5}$
}

${ }^{1}$ Department of Child Neurology, Hospital Infantil Sabará, Brazil

${ }^{2}$ Department of Neuroradiology, Hospital Infantil Sabará, São Paulo, Brazil

${ }^{3}$ Department of Nuclear Medicine, Hospital Sírio-Libanês, São Paulo, Brazil

${ }^{4}$ Department of Neurosurgery, Hospital Infantil Sabará, São Paulo, Brazil

Submission: January 30, 2018; Published: August 22, 2018

*Corresponding author: Conceição Campanario da Silva Pereira, Chief, Child Neurologist, Instituto Pensi (Pesquisa e Ensino em Saúde Infantil), Hospital Infantil Sabará, Avenida Angélica, São Paulo, Brazil; Tel: 55-11-2155-9364; Email: conceicaocampanario@terra.com.br

\begin{abstract}
This is a case report of a child, at the age of 3 years old with symptoms of chorea, at the left side and worsening of the hyperactivity, and the expressive language. The magnetic resonance image (MRI) and magnetic resonance angiography (MRA) performed revealed lenticulostriate stroke and severe stenosis of the right middle cerebral artery (MCA), M1 portion. After two months, a remarkable worsening at the MCA, with reduction of flux at the distal branches and It was done the encephalo-duro-arterio-synangiosis (EDAS) procedure with a graft of the superficial temporal artery. After 8 months, a single photon emission tomography (SPECT) was done, with moderate perfusional asymmetry with reduced blood flow mostly in right middle cerebral artery (rMCA) territory. The SPECT done 16 months after, the first one, show ed a clear improvement of the blood flow to the rMCA territory, and minimal perfusional asymmetry between right and left hemispheres

Keywords: lenticulostriate stroke; Single photon emission tomography; Magnetic resonance image; Stenosis; Middle cerebral artery; antithrombin; infections; recurrence; Zoster Virus; arteriopathies; territory; International Pediatric Stroke; MoyaMoya Disease; Acute Ischemic Stroke; Focal Cerebral Arteriopathy; Ischemic Attack

Abbreviations: MRA: Magnetic Resonance Angiography; MCA: Middle Cerebral Artery; MRI: Magnetic Resonance Image; rMCA: Right Middle Cerebral Artery; EDAS: Encephalo-Duro-Arterio-Synangiosis; AIS: Acute Ischemic Stroke; TCA: Transient Cerebral Arteriopathy; PVA: PostVaricella; SCD: Sickle Cell Disease; IPSS: International Pediatric Stroke Study; FCA: Focal Cerebral Arteriopathy; VZV: Varicella Zoster Virus; CMV: Cyto Megalo Virus; MMD: MoyaMoya Disease; TIA: Transitory Ischemic Attack
\end{abstract}

\section{Introduction}

The incidence of Acute Ischemic Stroke (AIS) in childhood, is at least 3.3/100.000. The diagnostic criteria for childhood arteriopathies include moyamoya, dissection, vasculitis, transient cerebral arteriopathy (TCA) and post-varicella (PVA) have been proposed by Sébire. The infarction in the lateral lenticulostriate territory as a result of unilateral intracranial arterial wall disease affecting the distal internal carotid arterial, proximal middle and /or anterior cerebral artery (MCA, ACA), is recognized as an important etiology of AIS, and TCA [1].
According to the conditions associated with stroke, we have: cardiological; hematological; cerebral arteriopathy; infections; genetic and toxic. Thrombophilia risk factors for stroke include variants factor2 (prothrombin) 20210, Factor 5 R506 (Factor $\mathrm{V}$ Leiden), antithrombin, protein $\mathrm{C}$, and protein $\mathrm{S}$ deficiency, variants of coagulation factor $\mathrm{V}(\mathrm{G} 1691 \mathrm{~A})$ and elevated lipoprotein have been found in small case series in children and infants. Also, Sickle Cell Disease (SCD) have 11\% risk of developing AIS and arteriopathies. The International Pediatric 


\section{Open Access Journal of Neurology \& Neurosurgery}

Stroke Study (IPSS) group has determined as Focal Cerebral Arteriopathy (FCA) of childhood, as the one with cerebral arterial stenosis with no apparent cause, representing the most common [2-4].

The term FCA describes the appearance of the angiography, with unilateral stenosis or vessel irregularity of proximal large intracranial arteries. The TCA represents the most used label for FCA 1. Other causes attributed to TCA: intracranial dissection, inflammatory $[5,6]$.

The TCA pathophysiological mechanism seems to be an acute vasculitis in a large and middle vessel induced by infections, viral and/or inflammation. Within 3 months following the infarct, there is unilateral, focal or segmental stenosis or even occlusion that involve the distal part of the intern carotid and initial segments and branches of the anterior cerebral artery (A1), middle cerebral artery (M1) or posterior cerebral artery (P1). Some cases, there is minimal stenosis, which increases to maximum stenosis or occlusion within 3 months In a prospective study by Fullerton, et al. [7]. the total of 56 children (16\%) has a recurrence of the stroke during follow-up [8].

Infectious due to Varicella Zoster Virus (VZV) has a known link to cause TCA [9]. It reveals a unilateral stenosis arteriopathy at the distal Internal Carotid Artery (ICA) and proximal segment of the Anterior Cerebral Artery (ACA) and middle cerebral artery (MCA), disclosing infarcts within the vascular territory of their lenticulostriate branches [10].

Multiples virus have been linked to arteriopathies and stroke in children. The IPSS have reported the association between minor recent infections and childhood arteriopathies $[11,12]$. In Study by Amlie-Lefond, et al. [4]. 25\% of the children with ischemic stroke, had Focal Cerebral Arteriopathy (FCA), which predictor was a recent upper respiratory infection. Other virus involved, parvovirus B19, cytomegalovirus (CMV), mycoplasma pneumonia, Borrelia burgdoferi, enterovirus, and Helicobacter pylori, can also be responsible for an acute large vessel vasculitis, and TCA [7].

In a study by Lanthier, et al. [13]. 26 children were eligible for AIS/Transitory Ischemic Attack (TIA) after varicella infection, despite the use of antithrombotics like aspirin or anticoagulant drugs. After spontaneous regression after up to 48 months, there was no restenosis, what suggests a monophasic course.

Another type of arteriopathy is the MoyaMoya Disease (MMD). Named it, because of the angiographic appearance of "puff and smoke". The angiographical diagnosis of moyamoya requires occlusion or stenosis, bilateral of the terminal ICA or its branches, associated with uni or bilateral abnormal collateral network of small lenticulostriate branches $[14,15]$.

The use of antithrombotic therapy varied among continents, with the predominant use of antiplatelet drugs. Moreover, multicenter outcomes of childhood AIS are limited. In the case of 79 children with unilateral arteriopathy, the anti-platelet medication was prescribed to four of five (80\%) of those with progressive arteriopathy, and to 58 of $74(78 \%)$ of patients with TCA. Antiviral and anti-thrombotic medication was prescribed in two children, and anti-coagulant in ten patients (14\%) of TCA, combined with antiplatelet treatment in four of them. Patients that received no treatment (4 of TCA group and one of progressive arteriopathy) had poor outcome $[15,16]$.

Nowadays, one of the indirect surgical procedures practice to vascularization is the encephalo-duro-arterio-synangiosis (EDAS). The EDAS involves freeing the superficial temporal artery, keeping its patency and attaching it to brain surface [17].

The mechanism of vascularization via indirect procedures may be adaptable to any type of chronic cerebral ischemia. At the early stage the indirect anastomosis, the angiogenesis promotes the spontaneous communication between the extracranial and intracranial arteries, in the operative wound, and granulation tissue. The two arterial systems allow the flow from the external carotid artery to the internal carotid artery systems. The cerebral perfusion imaging has become an important procedure in the diagnosis and treatment of MMD in children. The single photon emission tomography (SPECT) is known as a reference standard to evaluate the hemodynamic status in patients with MMD and also a good method to predict further clinical course in patients after revascularization surgery [17-21].

\section{Case Report}

The child VPMS, five years old, was born after an uneventful term pregnancy. He was a healthy child, with normal neurological development, except for the speech delay and hyperactivity. He was hospitalized at the age of 3 years old with symptoms of chorea at the left side, beside a worsening of the hyperactivity, and the expressive language, uncomprehensive at this point. At that time, he had good social interaction and chorea at the left side. There was no sign of pyramidal tract involvement, clonus, spasticity or cranial nerve impairment. It was referred by the parents, otitis and upper respiratory infection disease 2 weeks prior to the stroke event.

Initially was made a screening for Sydenham chorea, with ASLO antibodies, cardiologic exam, all unremarkable. The magnetic resonance image (MRI) performed at this point (July $1 \mathrm{st})$, revealed increased signal at diffusion-weighted imaging (DWI), in the right anterior basal ganglia, dominant at the caudate nuclei, anterior lentiform nuclei and anterior branch, and knee of the internal capsule (Figure 1). Other sparse small signals at diffusion-weighted were seen at the cerebral peduncle, transition parieto-occiptal, cortical and subcortical sites, all at the right side. At the right head of caudate nuclei was also revealed an intumescent region. The 3D-TOF (time of fight) MRA (july 6th) demonstrated severe stenosis of the right middle cerebral artery (MCA), more than $50 \%$ at the M1 portion (Figure $2)$. All this together favors the diagnosis of an acute ischemic stroke at the right lenticulostriate site. 


\section{Open Access Journal of Neurology \& Neurosurgery}

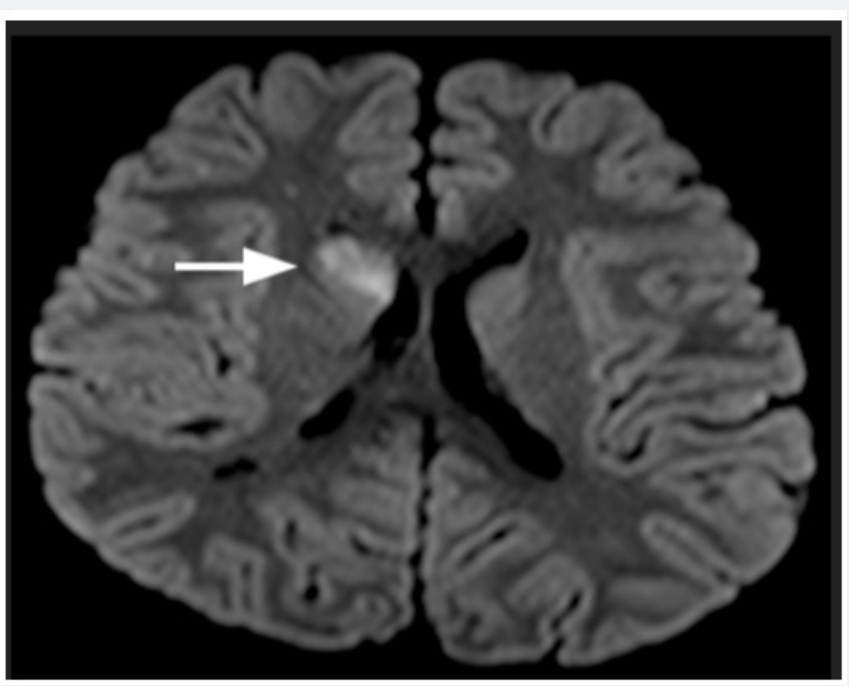

Figure 1: Acute ischemic stroke. Diffusion restriction at DWI in the right anterior basal ganglia.
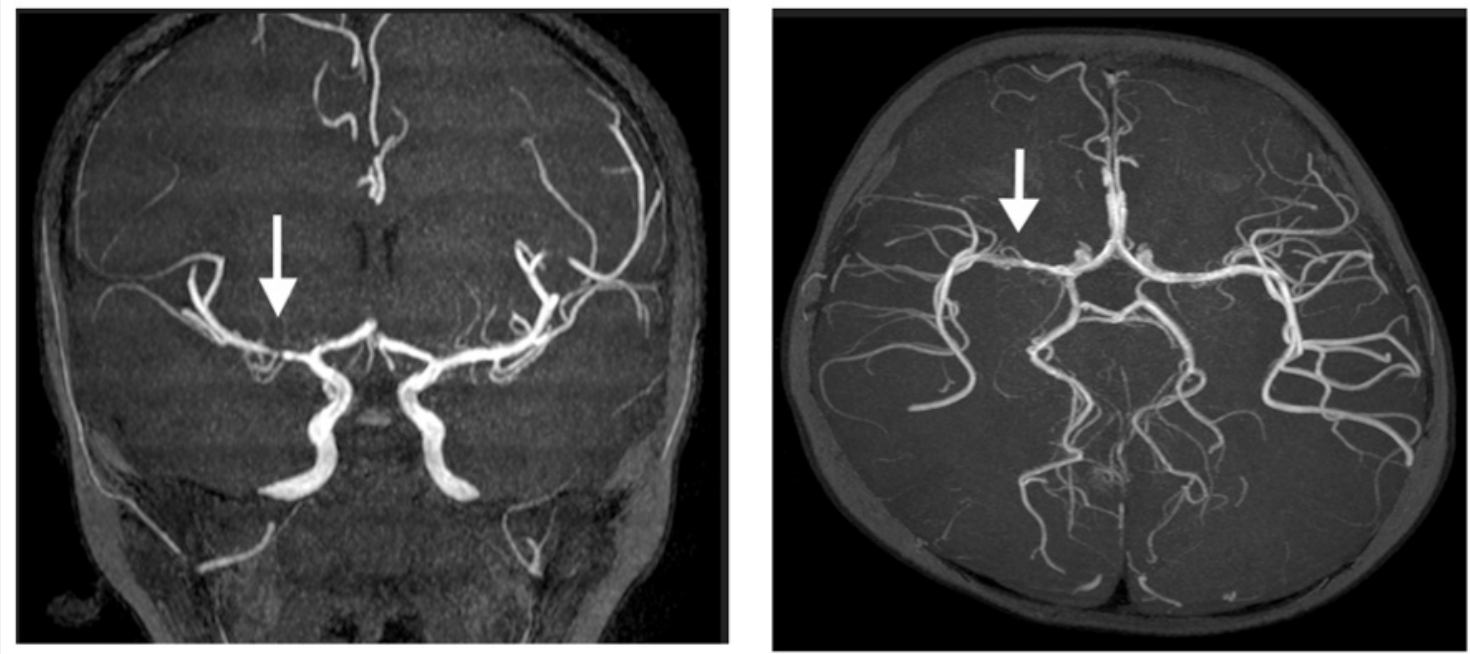

Figure 2: 3D-TOF MRA: (2A) coronal Maximum Intensity Projection (MIP), severe stenosis of the MCA; (2B) axial MIP, reduction of the degree of stenosis.

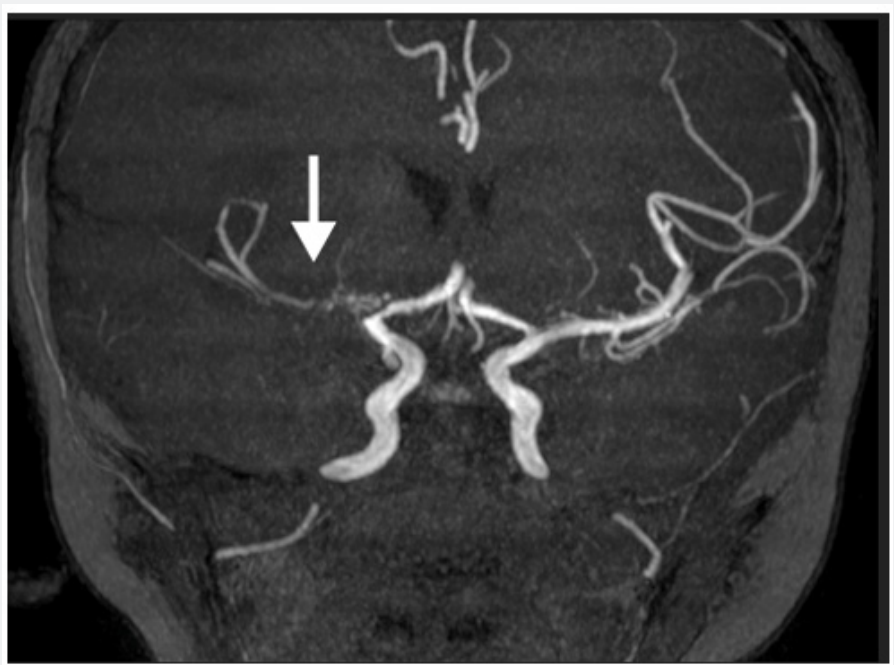

Figure 3: 3D-TOF MRA: coronal MIP, remarkable worsening to MCA, with reduction of flux at the distal branches. 


\section{Open Access Journal of Neurology \& Neurosurgery}

An extensive screening included hematologic, rheumatologic and infectious work-out, including thrombophilia risk factor, varicella zoster brain infection, and cardiological screening, what disclosed no abnormality. It was introduced AAS $100 \mathrm{mg}$ per day, Haloperidol for the chorea (weaned off after 2 months) and imipramine, for the hyperactivity disorder. A follow-up MRI, after 19 days (July 20th), revealed improvement of the ischemic stroke at the right lenticulostriate region with less tumescent effect. The MRA demonstrated reduction of the degree of stenosis of the right MCA (Figure 3).
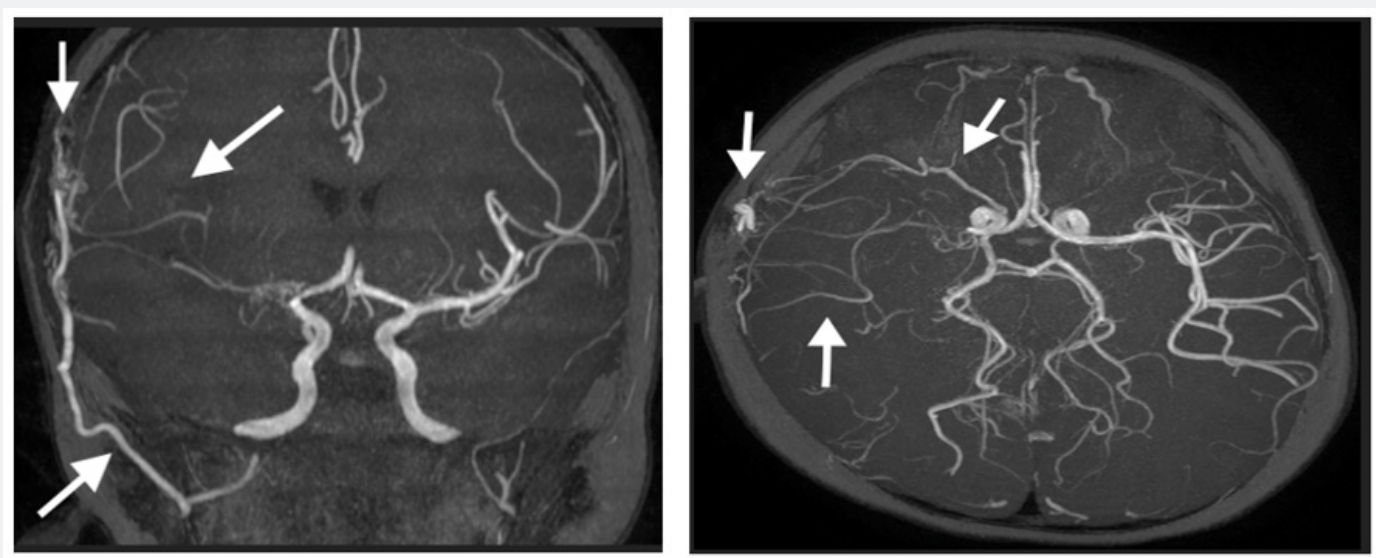

Figure 4: 3D-TOF MRA. Coronal (4A), Axial (4B): EDAS procedure, improvement of the caliber of the right superficial temporal artery, improvement of flux at post-stenosis branches of MCA.

A new MRA in September 29th, three months after the acute phase of the stroke, revealed remarkable worsening to MCA, with reduction of flux at the distal branches, in comparison to the last MRI (Figure 4). Also, there was an improvement at the right internal capsule and no new acute ischemic stroke. At this point, it was decided to the encephalo-duro-arterio-ynangiosis (EDAS) procedure with a graft of the superficial temporal artery. In March 2016, he had severe signs of hyperactivity and language disability. Several medicines were tried, as methylphenidate, imipramine, risperidone, fluoxetine, with unfavorable outcome. With the start on atomoxetine, there was a great improvement of his behavior related to hyperactivity, attention disorder, and language development.
In June 2016, when he was 4 years and 5 months, after 8 months following EDAS procedure, there was a remarkable improvement of the caliber of the right superficial temporal artery, now located inside the area of craniectomy at the right temporo-parietal region. There were new collateral transdural vessels in the surgical site. There is evidence of flow, by the collateral vessels, at the M2, M3 and M4 segments of the right MCA. There is an improvement of the flow by the new collateral of right middle meningeal and sphenoidal branches of the ophthalmic artery. Other small cortical collateral vessels from the posterior cerebral artery to MCA, were also evident (Figure 4).

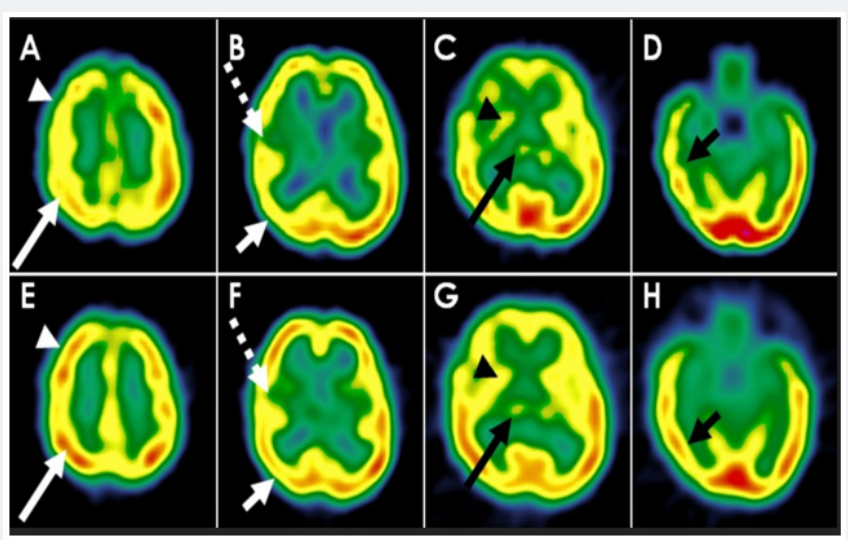

Figure 5: Transverse slices of two brain perfusion SPECT studies using ${ }^{99 m}$ TC-ECD performed in June/2016 (figures A-D) and October/2017 (figures $\mathrm{E}-\mathrm{H}$ ).

There is clear improvement of the blood flow to the right middle cerebral artery (rMCA) territory, including frontal (white arrowhead - A and E) and parietal (long white arrow - A and E) lobes, insula (dashed white arrow - B and F), temporoparietal cortex (short white arrow - B and F), thalamus (black arrowhead - C and G), striatum (long black arrow - C and G) and neocortical temporal lobe (short black arrow - D and H). The latter study reveals only minimal perfusional asymmetry between right and left hemispheres on posterior parietal (short white arrow - F) and neocortical neocortical temporal lobes (short black arrow - $\mathrm{H}$ ). 
In June 2016, a SPECT was done, and revealed a mild to moderate perfusional asymmetry with reduced blood flow mostly in right middle cerebral artery (rMCA) territory, including the posterior aspect of frontal lobe, insula, right parietal lobe, neocortical temporal lobe, thalamus, right basal ganglia (Figure 5). In July 2017, a new MRA and cranial MRI, with no additional aspects of collateral vessels or signs of strokes, with no image presented at this manuscript. In October 2017, the following SPECT showed a clear improvement of the blood flow to the rMCA territory, including frontal and parietal lobes, insula, temporoparietal cortex, thalamus, striatum and neocortical temporal lobe. At this study, a minimal perfusional asymmetry between right and left hemispheres on posterior parietal and neocortical temporal lobes was revealed (Figure 5). Now, he keeps some disfluency in his phrases, but some flaws in his phrases, in progress with phonotherapy and physiotherapy. A remarkable improvement in school abilities, with the benefit of his attention function. It is yet observed a subtle disability at the left superior and inferior limb, in fine movements.

\section{Discussion}

The acute treatment of stroke in children is supportive, although the secondary stroke prevention is done with either anticoagulation or antiplatelet therapies. Little is known about the efficacy and safety of therapies with thrombolytic in various ages groups, what demands further studies in order to understand the management, pathogenesis, and outcomes [11].

In our patient, despite the use of antiplatelet therapy, there was a progression of the stenosis arteriopathy at the MCA, after 3 months of the AIS the reason why was decided for the EDAS, to restores the flow at the MCA territory. The surgical treatment should be provided for children with MMD, in order to establish external carotid artery collateral circulation, preventing and treating ischemic damage in cerebral tissues and risks of new ischemic lesions. In other cases of chronic cerebral ischemia, vascularization via indirect procedures may be adaptable. Abnormalities of cerebral arterial circulation is present in eighty percent of children of AIS. Children from 1 month to 18 years old with AIS, who undergone investigation with MRI and MRA. In the total of 50 children, the most commonly artery involved was the MCA (38 patients). At an interval of 38 months, 5 children had recurrent clinical symptoms ( 2 with AIS and 3 with transitory ischemic attack). Three patients with progressive arteriopathy underwent external carotid to internal carotid by-pass surgery [1].

The great majority of children with AIS and anterior circulation intracranial arteriopathy suffer from TCA, probably of inflammatory etiology, and in $44 \%$ of cases, preceded by VZV infection. Many children developed worsening of arteriopathy, with later improvement or stabilization. In an acute vascular image with intracranial arteriopathy in children with AIS, the MRA should be repeated 3-6 months after the diagnosis and again at 6-12months [3].

\section{Conclusion}

In short, we report the case of a child, 3 years old with worsening of the stenosis of MCA after 3 months following the AIS, had remarkable improvement after 10 months he underwent EDAS surgery. We do not have determined the exact mechanism by which the vascular alterations appeared in our case, but we suppose that the upper respiratory infection prior to the vascular stenosis may have contributed to the vasculopathy.

The MRA, 8 months later the EDAS, revealed collateral vessels to MCA (M2, M3, M4), meningeal artery. Also, the SPECT, that initially, presented with mild to moderate perfusional asymmetry, reduced blood flow mostly in right middle cerebral artery (rMCA) territory, revealed remarkable improvement, after 16 months, with clear improvement of the blood flow to the rMCA territory, and minimal perfusional asymmetry between right and left hemispheres on posterior parietal and neocortical temporal lobes.

We conclude the indication, so far, of revascularization surgery, in cases, other than moyamoya disease, in which the flow to the cortex and the subcortical area is compromised, and the reliable use of MRA and SPECT to follow-up cases of stenosis. In this case, we could make a precocious diagnosis about the worsening of the stenosis and also, be sure about the success of the revascularization surgery months later.

\section{Declaration of Conflicting Interests}

The authors declare that there is no conflict of interest regarding the publication of this paper.

\section{References}

1. Danchaivijitt N, Cox TC, Saunder DE, Ganesan V (2006) Evolution of Cerebral Arteriopaties in Childhood Arterial Ischemic Stroke. Ann Neurol 59(4): 620-626.

2. Stoll M, Ruhle F, Nowak-Gottl U (2014) Advances in unerstanding stroke risk in children - a geneticist's view. British Journal of Haematology 164(5): 636-645.

3. Kenet G, Luthhoff LK, Albisetti M, Bernard T, Bonduel M, et al. (2010) Impact of thrombophin on risk of arterial ischemic stroke or cereral sinovenous thrombosis in neonates and children: a systematic review and meta-analysis of observational studies. Circulation 121: 18381847.

4. Amlie-Lefond C, Bernard TJ, Sebire G, Friedman NR, Heyer GL, et al. (2009) Prdictor of cerebral arteriopathy in children with arterial ischemic stroke: results of the International Pediatric Stroke Study. Circulation 119(10): 1417-1423.

5. Tolani AT, Yeom KW, Elber J (2015) Focal Cerebral arteriopathy: The Face with Many Names. Pediatric Neurology 53(3) :247-253.

6. Sébire G (2006) Transient cerebral arteriopathy in childhood. The Lancet 368: 8-10.

7. Fullerton HJ, Wintermark M, Hills NK, Dowling MM, Tan M, et al. (2016) Risk of Recurrenct Arterial Ischemic Stroke in Childhood: A Prospective International Study. Stroke 47(1): 53-59.

8. Sebire G, Fullerton H, Riou E, Deveber G (2004) Toward the definition of cerebral arteriopathies of childhood. Curr Opin Pediatr 16(6): 617622. 


\section{Open Access Journal of Neurology \& Neurosurgery}

9. Gilden D, White T, Khmeleva N, Heintzman A, Choe A, et al. (2015) Prevalence and distribution of VZV in temporal arteries of patients with giant cell arteritis. Neurology 84(19): 1948-1955

10. Askalan R, Laughlin S, Mayank S, Chan A, MacGregor D, et al. (2001) Chickenpox and stroke in child hood: a study of frequency and causation. Stroke 32(6): 1257-1262.

11. Fox CK, Fullerton HJ (2010) Recent Advances in Childhood Arterial ischemic Stroke. Curr Atheroscler Rep 12(4): 217-224.

12. Hills NK, Johnston SC, Sidney S, Zielinski BA, Fullerton HJ (2012) Recent trauma and acute infection as risk factors for childhood arteria ischemic stroke. Ann Neurol 72(6): 850-858.

13. Lanthier S, Armstrong D, Domi T, deVeber G (2005) Post-varicella arteriopathy of childhood. Natural history of vascular stenosis. Neurology 64(4): 660-663.

14. Starke RM, Komotar RJ, Hickman ZL, Paz YE, Pugliese AG, et al. (2009) Clinical features, surgical treatment, and long-term outcome in adult patients with moyamoya disease. Clinical article. J Neurosurg 111(5) 936-942.

15. Braun KPJ, Bulder MMM, Chabrier S, Kirkham FJ, Uiterwaal CSP, et al. (2009) The course and outcome of unilateral intracranial arteriopathy in 79 children with ischaemic stroke. Brain 132(pt2): 544-557.
16. Goldenberg NA, Bernard TJ, Fullerton HJ, Gordon A, deVeber G (2009) Antithrombotic treatments, outcomes, and prognostic factors in acute childhood-onset arterial ischaemic stroke: a multicentre, observational, cohort study. Lancet Neurol 8(12): 1120-1127.

17. Piao J, Wu W, Yang Z, Yu J (2015) Research Progress of Moyamoya Disease in Children. Int J Med Sci 12(7): 566-575.

18. Mukawa M, Narial T, Inaji M, Tamada N, Maehara T, et al. (2016) First autopsy analysis of a neovascularized arterial network induced by indirect bypass surgery for moyamoya disease: a case report. J Neurosurg 124(5):1211-1214.

19. Matsushima Y (1996) moyamoya disease. In: Youmans JR (Ed). Youman Neurological Surgery, ( $4^{\text {th }}$ ed). Philadelphia: Saunders.

20. Lee SK, Kim DI, Jeong EK, Kim SY, Kim SH, et al. (2003) Postoperative evaluation of Moyamoya Disease with Perfusion-Weighted MR Imagin: Iniciatial Experience. AJNR Am J Neuroradiol 24(4): 741-747.

21. So Y, Lee HY, Kim SK, Lee JS, Wang KC, et al. (2005) Prediction of the Clinical Outcome of Pediatric Moyamoya Disease with Postoperative Basal/Acetazolamide Stress Brain Perfusion SPECT after revascularization Surgery. Stroke 36(7):1485-1489.

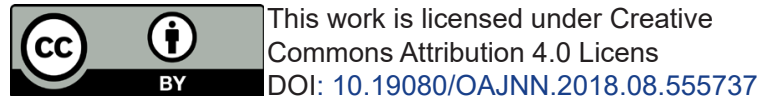

Your next submission with Juniper Publishers
will reach you the below assets
- Quality Editorial service
- Swift Peer Review
- Reprints availability
- E-prints Service
- Manuscript Podcast for convenient understanding
- Global attainment for your research
- Manuscript accessibility in different formats
( Pdf, E-pub, Full Text, Audio)
- Unceasing customer service
Track the below URL for one-step submission
https://juniperpublishers.com/online-submission.php

